\title{
TEACHING LINEAR ALGEBRA TO STUDENTS OF ECONOMIC AND TECHNICAL SPECIALTIES: SIMILARITIES AND DIFFERENCES
}

\author{
Evgenia V. Volodina ${ }^{1}$ Elena G. Efimova ${ }^{2}$, Alevtina G. Kulagina ${ }^{3^{*}}$ \\ Olympiada L. Taranova ${ }^{4}$, Marina E. Sirotkina ${ }^{5}$, Svetlana A. Yardukhina ${ }^{6}$ \\ ${ }^{1}$ Assoc. Prof., Chuvash state University, Russia, evg_volodina@mail.ru \\ ${ }^{2}$ Assoc. Prof., Chuvash state University, Russia, eg-fmf@mail.ru \\ ${ }^{3}$ Assoc. Prof., Chuvash state University, Russia,agkulagina11@gmail.com \\ ${ }^{4}$ Senior lecturer, Chuvash state University, Russia, otaranova80@gmail.com \\ ${ }^{5}$ Assoc. Prof., Chuvash state University, Russia, sirotkina-me@yandex.ru \\ ${ }^{6}$ Assoc. Prof., Chuvash state University, Russia, s-yard@mail.ru \\ ${ }^{*}$ Corresponding Author
}

\begin{abstract}
Currently, training of students of any specialty at the university implies the formation of professional competencies. "Linear algebra" is given particular place in this process. After studying this subject students should be able to use the acquired fundamental knowledge in their future professional activities. In addition, students should have the ability to determine general forms and patterns in linear algebra issues. An important role in the process of training specialists is played by the ability to mathematically correctly set science or economic problems, for this it is necessary to have a good understanding of the statements of classical mathematical problems in general. With a high-quality assimilation of the material and a sufficiently good ability to apply it in the required situation, students of technical specialties can plan and carry out pedagogical activities in the future, taking into account the specifics of the subject area in educational organizations. After studying at the university, specialists should be focused on both theoretical and applied activities. The increased requirements for the quality of graduate training are applied to both economic and technical specialties. In this regard, the modular approach to teaching the subject is gaining weight. The ability to develop modules of the same subject that are different in content and complexity for different specialties is of key importance in the training of technical and economic students. Students can immediately work out the practical application of the studied material on examples from their particular specialty, paying sufficient attention to the analysis of various specific nuances without spending too much time on analyzing general examples. The article deals with the issues related to teaching of "Linear algebra" to students of economic and technical specialties of the Chuvash State University, the similarities and differences in the presentation of the material. The main focus is on modern approaches in teaching the discipline and modular approach as well.
\end{abstract}

Keywords: linear algebra, formal approach, active approach, economic specialties, technical specialties, professional competencies, modular training.

\section{INTRODUCTION}

When studying at a higher educational institution in any faculty, mathematical sciences are considered the most "terrible" disciplines for students. At the same time every student understands that it is impossible to study physics, programming, computer science and a number of technical and economic subjects without 
mathematical sciences. As M. V. Lomonosov said: "Mathematics should be taught because it puts the mind in order." And he wasn't a mathematician. He was a natural scientist, physicist, chemist, metallurgist, geographer, astronomer, geologist, philologist, historian, artist, poet, and encyclopedist. Since ancient times to the present day all scientists realize that the development of other sciences is very difficult without mathematics. Mathematics develops thinking, logic, it teaches to analyze and systematize information, helps to abstract from real problems and translate research into the language of formulas and schemes.

Different methods are used to organize students ' learning and to control the assimilation of the material, depending on what the teacher has chosen. The classification of teaching methods is based on different postulates, but as a basis it is possible to take the classification proposed by the mathematician, doctor of pedagogical sciences, academician Y. K. Babansky in the $20^{\text {th }}$ century (Babansky, 1983, p. 608). The methods are as follows:

- Methods of organizing and implementing educational and cognitive activities: verbal (oral presentation, work with a book, lecture, explanations, etc.), visual (illustrations, demonstrations), practical (reproductive, creative, diagnostic exercises), active laboratory(interaction of the student with the teacher), interactive (interaction of students with each other);

- Methods of stimulating and motivating educational and cognitive activity (methods of forming interest, duty and responsibility in learning);

- Methods of control and self-control (oral, written, machine, practical, combined control, self-control).

In connection with the ever-growing requirements for the training of specialists, the shortcomings of traditional methods of teaching mathematics are increasingly revealed. General statements of problems without specifying particular results lead to the fact that students may be well versed in the theoretical aspects of the subject, but they have a poor understanding of how to apply this theory in specific practical problems. Intersubject connections are usually poorly covered, and when solving problems of applied mathematics, the student cannot recognize the very theoretical points in them that he perfectly understood in the process of studying. Monotony, formalism, haphazardness as well as lack of consideration for the characteristics of students and their creative potential lead to insufficient development of students.

New educational standards based on a competency approach require the construction of curricula which is aimed at expected learning outcomes, and not at the required amount of material studied. This leads to the cooperation of the teacher with the student, to the activity of the student himself, to greater independence on the part of the student. The teacher acts as an organizer of the student's cognitive process. You can prepare a training session with the use of active teaching methods such as a discussion on the topic of a lecture, an olympiad, a scientific and practical conference, practical research work with the development of solutions to a specific production task, etc.

At the Chuvash State University the discipline "Linear algebra" is taught in all technical and economic specialties. The question arises: how to present the same theoretical material to students so that everyone feels the importance of using this discipline in the practical solution of problems in their specialty. According to the new training standards, independent work of students takes the main place in the process of mastering professional competencies. This means that in lectures and practical classes, the teacher will only have time to pose a problem and outline the range of tasks to be solved, to outline ways to solve them along with familiarizing the problems with the main sources of information. A detailed study of the topic and analysis of possible tasks will be performed by the student independently. So what are the similarities and differences in teaching "Linear algebra" to students of technical and economic specialties?

\section{ABOUT MODERN APPROACHES IN THE ORGANIZATION OF THE EDUCATIONAL PROCESS}

Lecturers are helped by modern approaches, methods and technologies when teaching any subject, including "Linear algebra", to students of different specialties. The research approach involves the introduction of general methods and specific methods of scientific research into the educational process at all stages, as well as the implementation of search and creative activities. This process contributes to the formation of teacher-student relationships in the form of cooperation together with development and strengthening of self-education skills. The student's activity is formed in the categories of "know", "understand"," apply"," analyze", "evaluate", "synthesize" as part of implementing the activity approach in the process of education,. The student himself searches, studies and analyzes various sources of information, statistical data, text and image editors, and other educational resources. This also contributes to the active cognitive activity of the student. The acquired skills of independent work in the study of subjects lead to the expansion of independent students' work aimed at obtaining knowledge and skills not separately, 
but in their relationship with each other.

It is worth noting that a communicative approach to learning can be common for all specialties in teaching "Linear algebra". The ability to communicate through the language of the subject, to express personal point of view in a group work should be formed when studying both in technical or economic specialty. Specialists in particular field who are able to competently and compactly convey information of any nature to their colleagues are much more often in demand in the labor market than average university graduates.

When writing a final qualification paper, very often students of different specialties use the knowledge gained in the course of studying "Linear algebra". Working on projects involves processing large amounts of data, which means that it is extremely difficult to perform such calculations manually. The skills of using information and communication technologies which were acquired in the course of training are of great assistance. The student must find the necessary information for research in the media and on the Internet, he also should process the data and judge their accuracy, reliability and importance; ability to work with spreadsheets, graphics and other applications as well as communicating through electronic communication channels are necessary.

When organizing training, it should be borne in mind that it is necessary to take into account the characteristics of students. This requires the creation of different learning conditions for different groups of students as well as a differentiated approach to teaching the subject, which is manifested in tasks of different complexity and different types of assistance from the teacher.

Experts in the field of teaching mathematics note that in order to fully master mathematics you must have a number of abilities: the ability to understand the formal structure of the problem, the ability to generalize mathematical actions, flexibility of mind and mathematical memory (remember mathematical definitions, relationships, methods, principles, etc.). Using the formal language of mathematics allows you to transfer verbal descriptions and reasoning in economics or any other field to the field of operating with formulas. At the same time, there is an excellent opportunity to obtain new formulas and relations with the required properties, to generalize various forms of process representation, regardless of their content. Formal language allows you to understand the information on the same topic given by different authors. Finally, computer technologies are developing and facilitating calculation of economic, technical and other processes thanks to the formal language.

The solution of systems of linear equations, operations on matrices, and calculation of determinants are formal in nature. The essence of these actions becomes clear when they are applied to solving real problems. Teaching "Linear algebra" should be moderately simple, comprehensible and reasonable. Students of economic specialties need to be explained concepts on an intuitive level while accompanying them with visual examples. Students of technical specialties should work more with strict mathematical concepts, since these students often have to work with the language of formulas when compiling algorithms, programs and developing various theoretical projects. Misunderstanding of the mathematical language can lead to serious errors.

In the process of teaching "Linear algebra", it is necessary to constantly monitor the quality of students' knowledge. They must correctly understand the meaning of the basic concepts, relations between objects, methods and techniques of this subject. Students should memorize the designations of mathematical concepts and the design of mathematical ideas, while clearly understanding their meaning and content. Otherwise, there is a gap between the formal side of the subject and its practical application. Simple memorizing of definitions, theorems and formulas leads to a superficial assimilation of the discipline without possessing the skills and abilities prescribed in general standards. In part, this problem comes from the school years. The secondary school does not pay enough attention to deciphering what different symbols and formulas mean. Therefore, at the university the student does not see much difference between the notation of the matrix and the determinant and transfers the properties of operations on matrices to determinants, etc. without analyzing. Students of technical specialties should be given determining linear dependency of vectors both in a formal setting (there are numbers not simultaneously equal to zero, for which the vector equality turns to the zero vector), and the other, more understandable setting (one of the vectors is linearly expressed through others). Students of economic specialties better understand the second definition, and therefore in solving problems the emphasis should be placed on it. The analysis of such situations is in favor of a combined approach in teaching the discipline. The formal approach in teaching the subject should be combined with the activity approach, so that there are no gaps in the knowledge of students.

\section{MODULAR TRAINING}

According to education standards, graduates of economic specialties should master the applied direction of 
the "Linear algebra" course, while students of technical specialties should be well versed in theoretical issues as well. The requirements of the standard are well implemented by modular training. Modular training emerged in pedagogics at the end of the last century. It is described in detail in the works of P. A. Savicheva, Casanova M. A., I. P. Volkov, A. A. Guzinski etc (Volkov, 1990, p.160; Choshanov, 1996, p.160; Juceviciene, 1989, p. 271; Vasilyeva, 2019). Modules are logically completed parts of "Linear algebra", the study of which takes place in the allotted time interval. To a greater extent, modular training is focused on the student's independent work, it teaches self-organization and self-control. With modular training, communication between the teacher and the student changes: the teacher acts as a consultant, a tutor, and often such communication can be organized in a remote form. In modular training, an activity-based approach is well combined with individual and differentiated approaches. Within each module, the work can be divided into four parts: an oral presentation of the main concepts and questions by the teacher, independent work of students with information sources and seminars, repetition and generalization of the studied material, testing and evaluation of knowledge, skills and abilities using a rating system for assessing knowledge.

The content of the modules can be changed depending on which specialty they are intended for: economic or technical. For example, you can create the following modules: "Matrices", "Determinants", "Systems of linear equations", "Vector spaces", "Linear operators", "Quadratic forms". For students of technical specialties, you can use more formulas, theorems and problems of a theoretical nature, but do not forget the applied side of the discipline, for example, "Analytical geometry on the plane and space; the surface of the second order". Technical students can be invited to conduct research in normalized and metric spaces, to understand the consistent and subordinate norms of operators, to consider incorrectly posed problems of solving systems of linear equations with the introduction of a pseudo-inverse matrix and a normal pseudosolution of the system. Students of economic specialties should not consider theoretical tasks, they can have more practical laboratory work. For students of economics you can offer to perform practical work based on the application of the Leontiev model or the international trade model as a control of knowledge and skills, this done after mastering the modules.

Note the obvious advantages of modular training for students. First of all, this is the individual pace of work of each student on an individual curriculum. The goal is to master the module as a whole, and not one single topic within particular time. The ability to choose the level of training allows you to return to any module again to study it in a more complex formulation. With a conscientious attitude to study, the student has the right to count on achieving a high level of final results. In addition, modular training allows you to quickly identify existing knowledge gaps. An equally important advantage of modular training is the reduction of stressful situations during the period of passing tests and exams, since the final assessment of the discipline is set on the basis of the sum of points obtained during the study of each module. The advantages of modular training include the development of students ' communication skills both with each other and with the teacher, as well as the skills of working with information sources in an electronic environment.

There are not so many advantages of modular training for teachers. The main thing is that you do not need to prepare training material, lecture notes, to work out detailed classes on each topic. It is enough to highlight the main points in each topic, highlight the range of issues being studied, suggest suitable basic literature and conduct consultations throughout the study of the module. Also, the advantages include the unusual format for taking tests and exams. The teacher controls the assimilation of the material for each module separately throughout the course.

The disadvantages of modular training can be referred more for teachers than for students. Nevertheless, the disadvantages of modular training for students include a high level of independent work. Constant selfmonitoring of the acquired knowledge requires filling the gaps by re-studying the material, which students are not always ready for. The problem for students is determined in the lack of material and technical support, inconvenient media and presentation tools that the teacher will recommend to students based on the developed curriculum. Due to the lack of extensive life experience, not every student can rethink his activities and set higher goals for himself during the study process.

The disadvantages of modular training for teachers include a huge methodological work in the design of modules for independent learning of students. These developments require high pedagogical and methodological training of the teacher together with studying special teaching materials and training manuals. There is always a possibility that the training material will be put together incorrectly, there is always a subjective approach in the construction of modules. If the module is not large, then the creative potential of the student remains unclaimed. And if it is excessively large, then even gifted students will not easily master it in the allotted time. The disadvantages include the slow introduction of interactive teaching methods due to the lack of a sufficient number of teachers who have extensive experience in the environment of new educational technologies. Examination and test tasks should be developed by a group of methodologists of the graduating department in accordance with the requirements of the educational 
standard for the formation of certain competencies. Social and psychological adaptation can be considered a common problem for the introduction of modular training. It takes time for changes in the minds of teachers and students in relation to the new type of organization of the educational process.

Chuvash State University works in close contact with enterprises and organizations that are potential employers. These organizations offer students case studies on topics that are relevant to these organizations. The student submits his research plan for the problem, and if the organization is interested in it, the student receives a research supervisor from the organization. All further work is carried out by the student under the control of this supervisor. In the case of a complete solution of the case task, his project can be implemented in the work of this organization, and the student himself is invited to a permanent job after graduation. As the analysis of such case studies shows, many studies in various fields of economics, sociology, engineering, etc. are based on the processing of a large amount of data by means and methods of higher mathematics and linear algebra, among others. Therefore, high-quality learning, solution of multidisciplinary problems, development of creative abilities during studying the discipline play an important role in the formation of students as specialists in their particular field.

\section{CONCLUSIONS}

We can safely say that the formation of professional competencies in the study of "Linear algebra" in a higher educational institution can take place only with the combined efforts of the teacher and the student. Modern educational technologies are designed to help in the development of the discipline. Different approaches to teaching the discipline allow you to reveal the student's potential abilities. Modular teaching of the discipline is an innovative pedagogical technology that provides its own program of actions for the development of the studied material for each student; it helps in the development of independence, responsibility and talents of the student.

Enterprises and organizations that help the formation of demanded specialists on the labor market at every stage of their training are an integral part of the educational process. The possibility of an internship at a real enterprise helps a student to adjust the training in the direction of modern requirements for university graduates while studying at the University. The ability to establish a communicative relationship with the employer during the learning process reduces the period of adaptation of the student after graduation.

It is worth paying attention to the teaching of "Linear algebra" to students of technical and economic specialties, taking into account their fundamentally different professional direction, different applied orientation of the tasks being solved. But a student of any specialty should get the full amount of theoretical knowledge in the course of the discipline. The ability to adapt the studied material to solving real problems in the workplace in the future will be the quality of his training.

\section{REFERENCELIST}

Y. K. Babansky, T. A. Ilyina, N. A. Sorokin (1983). Pedagogics, p. 608.

I. P. Volkov (1990). There is one goal -there are many roads, p.160.

M. A. Choshanov (1996). Flexible technology of problem-based modular training, p.160.

P. A. Juceviciene(1989). Theory and practice of modular training, p. 271.

L. N. Vasilyeva, E. V. Volodina, I. I. Ilyina, (2019).Interdisciplinary tasks as a means of developing the professional competence of students in technical areas. Problems of modern education -online publication-All-Russian interdisciplinary journal, № 6. 